\title{
Body Dysmorphic Disorder, Psychiatric Symptoms, and Quality of Life in Female Dermatological Patients
}

This article was published in the following Dove Press journal: Neuropsychiatric Disease and Treatment

\author{
Ik-Seung Chee ${ }^{1,2}$ \\ Hyun-Jin $\mathrm{Kim} \mathbb{D}^{2}$ \\ Young Lee ${ }^{3}$ \\ Jee Wook Kim (iD ${ }^{4,5}$ \\ 'Department of Psychiatry, Chungnam \\ National University Hospital, Daejeon, \\ Republic of Korea; ${ }^{2}$ Department of \\ Psychiatry, Chungnam National \\ University Sejong Hospital, Sejong, \\ Republic of Korea; ${ }^{3}$ Department of \\ Dermatology, Chungnam National \\ University Hospital, Daejeon, Republic of \\ Korea; ${ }^{4}$ Department of Neuropsychiatry, \\ Hallym University Dongtan Sacred Heart \\ Hospital, Hwaseong, Gyeonggi, Republic \\ of Korea; ${ }^{5}$ Department of Psychiatry, \\ Hallym University College of Medicine, \\ Chuncheon, Gangwan, Republic of Korea
}

Correspondence: Jee Wook Kim Department of Neuropsychiatry, Hallym University Dongtan Sacred Heart

Hospital, 7 Keunjaebong-gil, Hwaseong-si, Gyeonggi-do 18450, Republic of Korea

Tel +823180862340

Fax +823180862029

Email kimakins@hanmail.net
Purpose: To examine the relationships of body dysmorphic disorder (BDD) with psychiatric symptoms and quality of life in dermatological patients.

Patients and Methods: A total of 154 female patients with dermatological disease underwent a comprehensive clinical assessment that included the Body Dysmorphic Disorder Examination-Self Report (BDDE-SR), Symptom Checklist 90-Revised (SCL-90-R), and Skindex-29. Dermatological disease was categorized as follows: inflammatory dermatoses (reference category), isolated lesions, and unclassified dermatoses. The BDDE-SR and SCL90-R scores were used to evaluate BDD and psychiatric symptoms, respectively. Dermatological quality of life was measured with the Skindex-29.

Results: The BDDE-SR score was significantly associated with the SCL-90-R and Skindex29 total and subscores, even after controlling for age, body mass index, and dermatological diagnosis. The variables that contributed most to the BDDE-SR score were the SCL-90-R depression score and Skindex-29 emotion scores. Additional analyses revealed that the BDDE-SR score was higher in participants with unclassified dermatoses, but neither the SCL-90-R score nor Skindex-29 score was related to any dermatological diagnosis.

Conclusion: The BDD symptoms were especially prominent in the unclassified dermatoses group and were highly related to psychiatric symptoms and a poor quality of life in our dermatological patients. Further research including studies involving psychiatric interviews to confirm the BDD diagnosis and symptoms will improve our understanding of BDD in dermatological patients.

Keywords: body dysmorphic disorder, psychiatric symptoms, quality of life: dermatological disease, unclassified dermatoses

\section{Introduction}

Body dysmorphic disorder (BDD) is a mental disorder characterized by an obsession with some aspect of one's own body or appearance perceived to be severely flawed, and therefore warranting exceptional measures to hide or fix. ${ }^{1}$ The Diagnostic and Statistical Manual of Mental Disorders, Fourth Edition (DSM-IV) defines BDD as a preoccupation with an imagined or trivial defect in appearance causing social or occupational dysfunction, and not better explained as another disorder. $^{2}$ The DSM-5 includes BDD in a new category (obsessive-compulsive spectrum) and adds operational criteria (such as repetitive behaviors or intrusive thoughts) and a new subtype of dysmorphia (muscle dysmorphia; belief that one's body is too small, or insufficiently muscular or lean). ${ }^{3}$ 
Most BDD patients seen in psychiatric settings have other mental disorders. Several studies have reported that major depressive disorder is the most common comorbid disorder, with the largest study reporting a current and lifetime rates of $58 \%$ and $76 \%$, respectively. ${ }^{4,5}$ Obsessivecompulsive disorder, substance use disorder, social phobia, and avoidant personality disorder also commonly co-occur with BDD. ${ }^{4,5}$ BDD patients experience unusually high levels of perceived stress and a poor quality of life. ${ }^{5-7}$ Health-related quality of life is a multi-dimensional construct reflecting overall wellbeing that includes aspects of physical and mental health and is self-defined according to the perceived ability to achieve and maintain a level of overall functioning that allows the patient to reach life goals. ${ }^{8,9}$ In a study assessing health-related quality of life using the Short Form Health Survey, outpatients with BDD had worse scores in all mental health domains than the general population and patients with depression. ${ }^{7}$ More severe BDD symptoms were associated with poorer mental health-related quality of life. ${ }^{5}$

Empirical studies suggest that the prevalence of BDD among dermatology and plastic surgery patients is higher than in the general population. ${ }^{10,11}$ In total, $12 \%$ of dermatology patients screened positive for BDD, ${ }^{10}$ compared to $7-8 \%$ of cosmetic surgery and in cosmetic surgery patients. ${ }^{11}$ According to Phillips et al, ${ }^{10}$ dermatologists may be the physicians most often seen by these patients. BDD seems to be more prevalent among dermatology and cosmetic surgery patients, thus showing the importance of professionals with knowledge of the clinical aspects of BDD.

We first aimed to examine the relationships of BDD with psychiatric symptoms and quality of life in dermatological patients. We secondly assessed the relationship between stratified dermatologic diagnosis and BDD, psychiatric symptoms, or quality of life.

\section{Patients and Methods}

\section{Participants}

A total of 154 female outpatients with a dermatological disease who visited to the dermatology outpatient clinic of a university hospital were enrolled in this study. The study protocol was approved by the Institutional Review Board of Chungnam National University Hospital, Daejeon, Republic of Korea. The study was conducted in accordance with the Declaration of Helsinki. All participants provided written informed consent.

\section{Dermatological Diagnoses}

All participants were diagnosed with a dermatological disease based on a clinical examination by a dermatologist. The dermatological disease categories were inflammatory dermatoses (reference category), isolated lesions, and unclassified dermatoses, as per previous studies. ${ }^{12-14}$

\section{Assessments of BDD, Psychiatric Symptoms, and Quality of Life}

All participants with dermatological disease underwent a comprehensive clinical assessment that included the Body Dysmorphic Disorder Examination-Self Report (BDDE-SR), Symptom Checklist-90-Revised (SCL-90-R), and Skindex-29; these instruments were used to evaluate BDD, psychiatric symptoms, and quality of life, respectively.

\section{BDDE-SR}

The BDDE-SR is a 30-item self-report questionnaire that determines the extent of dissatisfaction with body parts within the past month. ${ }^{15,16}$ Each question (except for questions 16a and b, which are answered "yes" or "no") is answered on a 6-point Likert scale. The total score ranges from 0 to 168 . Higher scores reflect more severe symptoms. The Korean version of the BDDE-SR has been tested in adolescents, ${ }^{17}$ and college students. ${ }^{18}$

\section{SCL-90-R}

The SCL-90-R is a self-report instrument comprising 90 items that psychological distress and current psychiatric symptoms (somatization, obsessive-compulsive disorder, interpersonal sensitivity, depression, anxiety, hostility, phobic anxiety, paranoid ideation, and psychoticism). ${ }^{19}$ Respondents provide answers based on the symptoms in the past week, including the day of the test, using a 5-point Likert scale. Higher scores mean higher level of symptoms. The Korean version of the SCL-90-R has been tested for reliability and validity. ${ }^{20}$

\section{Skindex-29}

The Skindex- $29^{21}$ is a 29 -item self-administered questionnaire that assesses the health-related quality of life of patients with skin diseases. It covers three domains: degree of symptoms, psychosocial functioning, and emotional status. $^{22}$ The questions are answered using a 5-point Likert scale, and mean scores for all items and individual domains are calculated (total and domain score, respectively), and higher scores mean higher level of symptoms. The Korean version of the Skindex-29 has been tested for reliability and validity. ${ }^{23}$ 


\section{BMI Assessment}

Body mass index (BMI) was calculated as weight in kilograms divided by the height in meters squared. Research nurses measured the height and body weight of all participants and calculated the BMI. BMI was categorized underweight $\left(<21 \mathrm{mg} / \mathrm{kg}^{2}\right)$, healthy weight $\left(21-25 \mathrm{mg} / \mathrm{kg}^{2}\right)$ or overweight $\left(>25 \mathrm{mg} / \mathrm{kg}^{2}\right)$ in accordance with a previous report. ${ }^{24}$

\section{Statistical Analysis}

Demographic and clinical variables were compared among groups using analysis of variance for continuous variables and the $\chi^{2}$ test for categorical variables. To examine the relationship of BDD with psychiatric symptoms or quality of life, multiple linear regression analysis with BDDE-SR score as the independent variable and SCL-90-R and Skindex-29 scores as the dependent variables were performed, including an analysis stratified according to dermatological diagnosis using inflammatory dermatoses as the reference (inflammatory dermatoses vs isolated lesions and inflammatory dermatoses vs unclassified dermatoses). Three models were devised: the first included no covariates, the second included age as a covariate, and the third included age, BMI, and the dermatological diagnosis as covariates. Furthermore, to identify variables contributing to BDD, stepwise multiple linear regression analyses with the SCL-90-R and Skindex-29 subscores as independent variables and the BDDE-SR score as the dependent variable was conducted. Statistical analyses were performed using IBM SPSS Statistics software (ver. 24.0; IBM Corp. Armonk, NY, USA). A p-value $<0.05$ was considered significant.

\section{Results}

\section{Participant Characteristics}

The demographic and clinical characteristics of the participants are presented in Table 1. Among the total 154 female participants with a dermatological diagnosis, 96 had inflammatory dermatoses [acne, $\mathrm{n}=38$; atopic (eczematous) dermatitis, $\mathrm{n}=$ 22; allergic contact dermatitis, $\mathrm{n}=12$; urticaria, $\mathrm{n}=6$; seborrheic dermatitis, $\mathrm{n}=5$; psoriasis, $\mathrm{n}=5$; xeroderma, $\mathrm{n}=2$; Behçet's disease, $\mathrm{n}=1$; ringworm, $\mathrm{n}=1$; herpes zoster, $\mathrm{n}=1$; candidiasis, $\mathrm{n}=1$; folliculitis, $\mathrm{n}=1$; mycosis fungoides, $\mathrm{n}=1$ ]; 28 had isolated lesions (melasma, $\mathrm{n}=11$; freckles, $\mathrm{n}=5$; warts, $\mathrm{n}=3$; blemishes, $\mathrm{n}=3$; solar lentigo, $\mathrm{n}=2$; syringoma, $\mathrm{n}=1$; dermatofibroma, $\mathrm{n}=2$; or spots, $\mathrm{n}=1$ ), and 30 had unclassified dermatoses (alopecia, $\mathrm{n}=23$; vitiligo, $\mathrm{n}=3$; facial flushing, $\mathrm{n}=2$; telogen effluvium, $\mathrm{n}=1$; trichotillomania, $\mathrm{n}=1$ ) (Table 1).

Table I Participant Characteristics by Stratified Dermatological Diagnoses $(\mathrm{N}=154)$

\begin{tabular}{|c|c|c|c|c|c|c|}
\hline Characteristics & Overall & Inflammatory Dermatoses & Isolated Lesions & Unclassified Dermatoses & $\chi^{2}$ or $F$ & $P$ \\
\hline $\mathrm{n}, \%$ & 154 & $96(62.3)$ & $28(18.2)$ & $30(19.5)$ & & \\
\hline Age, $y$ & $34.85(9.2)$ & $32.35(8.0)$ & $40.75(8.5)$ & $37.33(10.4)$ & 11.945 & $<0.001$ \\
\hline $\mathrm{BMI}, \mathrm{kg} / \mathrm{m}^{2}$ & $21.55(2.6)$ & $21.09(2.5)$ & $22.15(2.6)$ & $22.48(2.6)$ & 4.097 & 0.019 \\
\hline BDD global score & $69.27(23.9)$ & $67.57(23.3)$ & $66.54(20.6)$ & $77.23(27.2)$ & 2.130 & 0.122 \\
\hline \multicolumn{7}{|l|}{ SCL-90-R } \\
\hline Total score & $437.61(107.8)$ & $433.76(93.6)$ & $430.64(143.6)$ & $456.43(115.2)$ & 0.574 & 0.565 \\
\hline Somatization score & $43.06(7.8)$ & $43.15(7.7)$ & $42.04(8.8)$ & $43.77(7.3)$ & 0.366 & 0.694 \\
\hline Obsessive-compulsive score & $43.4 \mathrm{I}(9.2)$ & $43.49(8.3)$ & $41.46(11.1)$ & $44.97(9.8)$ & 1.067 & 0.347 \\
\hline Interpersonal sensitivity score & $44.13(9.9)$ & $43.59(9.0)$ & $43.32(11.4)$ & $46.60(11.0)$ & 1.177 & 0.311 \\
\hline Depression score & $42.71(9.0)$ & $42.59(8.2)$ & $41.36(10.1)$ & $44.33(10.3)$ & 0.806 & 0.449 \\
\hline Anxiety score & $41.90(7.4)$ & $41.81(7.2)$ & $41.32(7.8)$ & $42.73(7.8)$ & 0.282 & 0.755 \\
\hline Hostility score & $45.20(8.7)$ & $45.06(7.9)$ & $45.11(11.0)$ & $45.73(8.8)$ & 0.070 & 0.933 \\
\hline Phobia score & $44.11(7.5)$ & $43.61(6.1)$ & $45.04(10.9)$ & $44.83(7.6)$ & 0.565 & 0.570 \\
\hline Paranoid score & $43.64(8.6)$ & $43.07(7.4)$ & 44.61 (11.7) & $44.57(9.1)$ & 0.555 & 0.575 \\
\hline Psychosis score & $42.72(7.4)$ & $41.98(5.5)$ & $43.43(11.0)$ & $44.43(8.6)$ & 1.406 & 0.248 \\
\hline General symptom index score & $46.72(42.0)$ & $45.40(36.7)$ & $44.96(54.6)$ & $54.47(44.9)$ & 0.669 & 0.514 \\
\hline \multicolumn{7}{|l|}{ Skindex-29 } \\
\hline Total score & $57.72(62.1)$ & $56.31(61.0)$ & $50.37(65.3)$ & $69.11(63.0)$ & 0.724 & 0.487 \\
\hline Symptom score & $19.85(20.6)$ & $19.11(21.0)$ & $17.63(21.6)$ & $24.27(18.1)$ & 0.914 & 0.403 \\
\hline Function score & 13.91 (19.7) & $12.96(18.6)$ & $13.99(22.3)$ & $16.88(20.7)$ & 0.452 & 0.638 \\
\hline Emotion score & $23.97(26.0)$ & $24.25(26.0)$ & $18.75(23.4)$ & $27.96(28.3)$ & 0.923 & 0.400 \\
\hline
\end{tabular}

Note: Unless otherwise indicated, data are expressed as mean (standard deviation).

Abbreviations: BMI, body mass index; BDD, body dysmorphic disorder; SCL-90-R, Symptom Checklist 90-Revised. 
Table 2 Results of Multiple Linear Regression Analyses for Assessing the Relationship Between BDD-SR and SCL-90-R Scores in Dermatological Patients

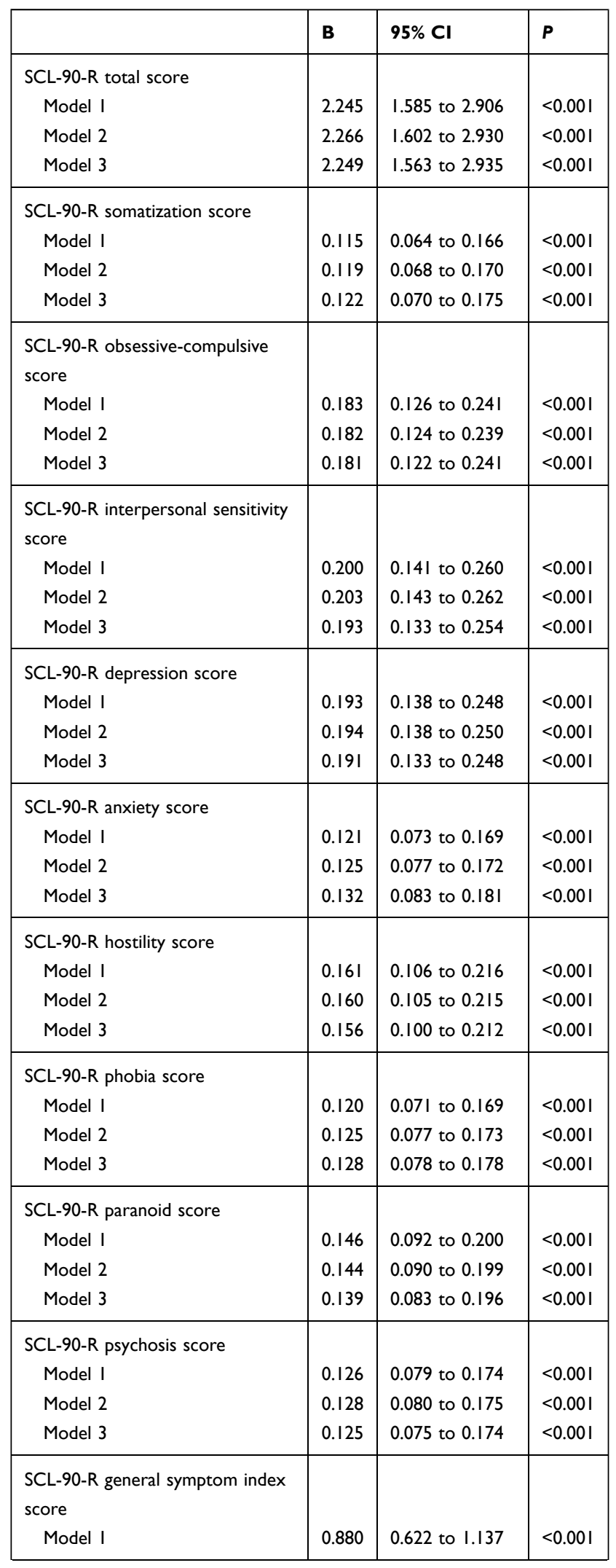

(Continued)
Table 2 (Continued)

\begin{tabular}{|l|l|l|l|}
\hline & B & $95 \%$ Cl & $P$ \\
\hline Model 2 & 0.887 & 0.629 to 1.146 & $<0.001$ \\
Model 3 & 0.882 & 0.615 to 1.149 & $<0.001$ \\
\hline
\end{tabular}

Note: Model I did not include any covariates, model 2 included age as covariate, and model 3 included all potential covariates, including age, body mass index, and dermatologic diagnosis.

Abbreviations: BDD-SR, Body Dysmorphic Disorder Examination-Self Report; SCL-90-R, Symptom Checklist 90-Revised; Cl, confidence interval.

\section{Association Between BDD and Psychiatric Symptoms}

The BDDE-SR score was significantly associated with the SCL-90-R total and subscores after adjusting for all potential covariates (Table 2).

\section{Association Between BDD and Quality of Life}

The BDDE-SR score was significantly associated with the Skindex-29 total and subscores after adjusting for all potential covariates (Table 3 ).

Table 3 Results of Multiple Linear Regression Analyses for Assessing the Relationship Between BDD-SR Score and Skindex-29 Score in Dermatological Patients

\begin{tabular}{|c|c|c|c|}
\hline & B & $95 \% \mathrm{Cl}$ & $\boldsymbol{P}$ \\
\hline \multicolumn{4}{|l|}{ Skindex-29 total score } \\
\hline Model I & 1.249 & 0.866 to $\mathrm{I} .63 \mathrm{I}$ & $<0.001$ \\
\hline Model 2 & 1.269 & 0.886 to 1.652 & $<0.001$ \\
\hline Model 3 & 1.278 & 0.883 to 1.673 & $<0.001$ \\
\hline \multicolumn{4}{|l|}{ Skindex-29 symptom score } \\
\hline Model I & 0.347 & 0.214 to 0.479 & $<0.001$ \\
\hline Model 2 & 0.352 & 0.219 to 0.485 & $<0.001$ \\
\hline Model 3 & 0.343 & 0.206 to 0.479 & $<0.001$ \\
\hline \multicolumn{4}{|l|}{ Skindex-29 function score } \\
\hline Model I & 0.385 & 0.265 to 0.506 & $<0.001$ \\
\hline Model 2 & 0.395 & 0.275 to 0.514 & $<0.001$ \\
\hline Model 3 & 0.403 & 0.279 to 0.527 & $<0.001$ \\
\hline \multicolumn{4}{|l|}{ Skindex-29 emotion score } \\
\hline Model I & 0.517 & 0.356 to 0.678 & $<0.001$ \\
\hline Model 2 & 0.522 & 0.361 to 0.684 & $<0.001$ \\
\hline Model 3 & 0.532 & 0.365 to 0.699 & $<0.001$ \\
\hline
\end{tabular}

Note: Model I did not include any covariates, model 2 included age as covariate, and model 3 included all potential covariates, including age, body mass index, and dermatologic diagnosis.

Abbreviations: BDD-SR, Body Dysmorphic Disorder Examination-Self Report; $\mathrm{Cl}$, confidence interval. 
Table 4 Results of Stepwise Multiple Linear Regression Analyses for Assessing Variables Contribute to BDD-SR Score in Dermatological Patients

\begin{tabular}{|c|c|c|c|c|c|}
\hline & B & SE & $95 \% \mathrm{Cl}$ & $\boldsymbol{P}$ & $R^{2}$ \\
\hline Model I & & & & & 0.251 \\
\hline SCL-90-R depression score & 1.324 & 0.186 & 0.958 to 1.691 & $<0.001$ & \\
\hline Model 2 & & & & & 0.321 \\
\hline SCL-90-R depression score & 0.928 & 0.204 & 0.525 to 1.330 & $<0.001$ & \\
\hline Skindex-29 emotion score & 0.279 & 0.071 & 0.139 to 0.419 & $<0.001$ & \\
\hline
\end{tabular}

Abbreviations: BDD-SR, Body Dysmorphic Disorder Examination-Self Report; SCL-90-R, Symptom Checklist 90-Revised; Cl, confidence interval.

\section{Variables Contributing to BDD}

The variables that contributed most to the BDDE-SR score were the SCL-90-R depression score and Skindex-29 emotion score (Table 4 and Figure 1).

\section{Association Among BDD, Psychiatric Symptoms, and Quality of Life Stratified by Dermatological Diagnosis}

The BDD-SR scores were highest in the unclassified dermatoses group, but neither the SCL-90-R nor Skindex-29 score were related to any dermatological diagnosis after adjusting for the covariates (Table 5 and Figure 2).

\section{Discussion}

The results of this study showed that BDD was associated with psychiatric symptoms and low quality of life in adult females with a dermatological disease. Furthermore, BDD symptoms were more severe in the unclassified dermatoses group, but neither psychiatric symptoms nor a low quality of life was related to any dermatologic diagnosis. To our

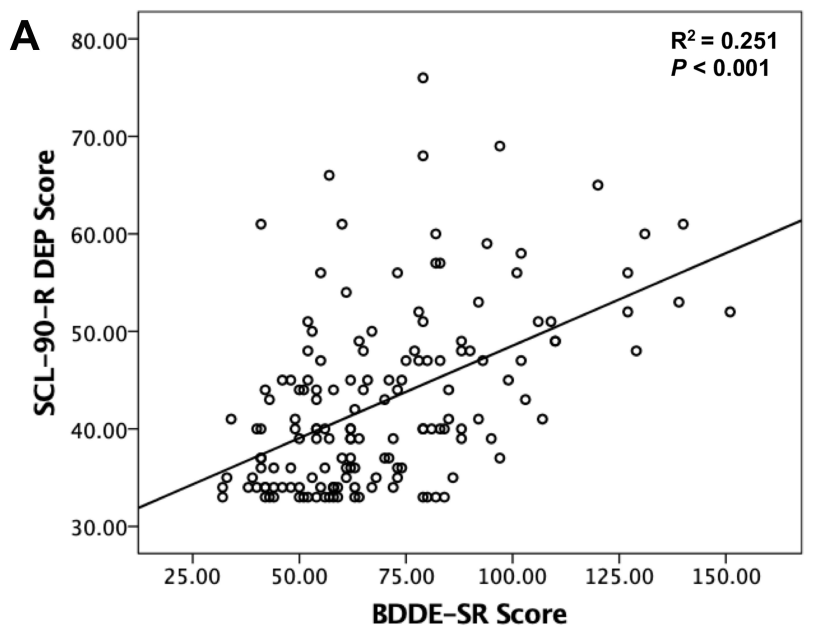

knowledge, this is the first study to investigate the relationships among BDD, global psychiatric symptoms, and quality of life via analyses stratified by dermatological diagnosis.

Our findings were consistent with previous studies regarding the relationships of BDD with depression and quality of life. ${ }^{7,25}$ One study reported that participants with skin diseases had more severe BDD score and depression, while those with a skin disease and severe BDD had high depression scores. ${ }^{25}$ In another study, BDD was frequently accompanied by major depression, earlier-onset depression and longer-duration depressive episodes, and also tended to co-occur with atypical depression. ${ }^{26}$ Another study on the relationship between BDD and quality of life showed that the BDD severity was correlated with quality of life even after adjusting for the severity of depression. ${ }^{7}$

Within our unclassified dermatoses group, and particularly among the patients with hair-related concerns, BDDE-SR scores were higher than those of the inflammatory dermatoses group, although neither psychiatric symptoms nor the quality of life was related to any dermatological diagnosis. One study reported that the incidence of BDD was about 10 times higher

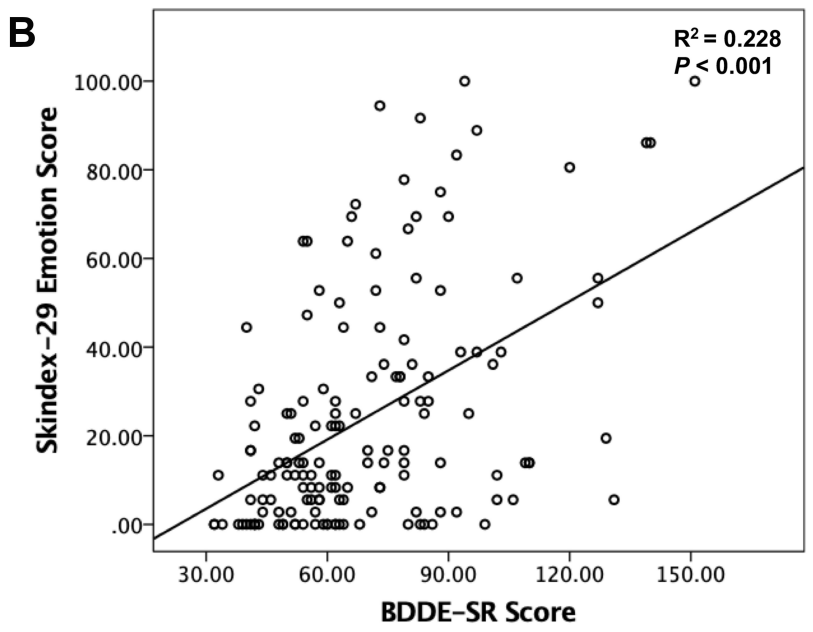

Figure I Scatter plots of the relationships of the BDDE-SR score with (A) the SCL-90-R depression score and (B) Skindex-29 emotion score. 
Table 5 Results of Multiple Linear Regression Analyses for Assessing the Relationship Between Stratified Dermatological Diagnoses and BDD-SR, SCL-90-R, or Skindex-29 Scores in Dermatological Patients

\begin{tabular}{|c|c|c|c|c|c|}
\hline & \multicolumn{5}{|c|}{ Stratified Dermatological Diagnoses } \\
\hline & \multirow[t]{2}{*}{ Inflammatory Dermatoses } & \multicolumn{2}{|l|}{ Isolated Lesions } & \multicolumn{2}{|l|}{ Unclassified Dermatoses } \\
\hline & & B (95\% Cl) & $\mathbf{p}$ & B $(95 \% \mathrm{Cl})$ & $\mathbf{P}$ \\
\hline \multicolumn{6}{|l|}{ BDD-SR score } \\
\hline Model I & Reference & $-0.519(-10.610$ to 9.571$)$ & 0.919 & $10.762(0.812$ to 20.713$)$ & 0.034 \\
\hline Model 2 & Reference & 1.901 ( -8.765 to 12.567$)$ & 0.725 & 12.338 (2.152 to 22.524$)$ & 0.018 \\
\hline Model 3 & Reference & $1.490(-9.097$ to 12.078$)$ & 0.781 & $10.440(0.134$ to 20.745$)$ & 0.047 \\
\hline \multicolumn{6}{|l|}{ SCL-90-R score } \\
\hline Model I & Reference & $-8.453(-55.612$ to 38.707$)$ & 0.724 & $18.595(-27.909$ to 65.099$)$ & 0.431 \\
\hline Model 2 & Reference & $-10.173(-60.331$ to 39.985$)$ & 0.689 & $17.475(-30.427$ to 65.377$)$ & 0.472 \\
\hline Model 3 & Reference & $-12.029(-61.863$ to 37.805$)$ & 0.634 & $8.890(-39.618$ to 57.399$)$ & 0.718 \\
\hline \multicolumn{6}{|l|}{ Skindex-29 score } \\
\hline Model I & Reference & $-7.786(-34.813$ to $|9.24|)$ & 0.570 & $9.612(-17.039$ to 36.263$)$ & 0.477 \\
\hline Model 2 & Reference & -11.701 ( -40.384 to 16.982$)$ & 0.421 & $7.063(-20.330$ to 34.456$)$ & 0.611 \\
\hline Model 3 & Reference & $-12.617(-41.195$ to $15.96 \mid)$ & 0.384 & $2.827(-24.991$ to 30.644$)$ & 0.841 \\
\hline
\end{tabular}

Note: Model I did not include any covariates, model 2 included age as covariate, and model 3 included all potential covariates, including age, body mass index, and dermatologic diagnosis.

Abbreviations: BDD-SR, Body Dysmorphic Disorder Examination-Self Report; SCL-90-R, Symptom Checklist 90-Revised; Cl, confidence interval.

in patients complaining of hair loss compared to general dermatology patients. ${ }^{27}$ That study emphasized that awareness of BDD and referral of selected patients to mental health professionals are crucial. Furthermore, many studies have reported that hair-related concern, and especially hair loss, is the most common BDD symptom. ${ }^{28-30}$

Among BDD patients receiving surgical and nonpsychiatric medical treatment, treatment outcomes are

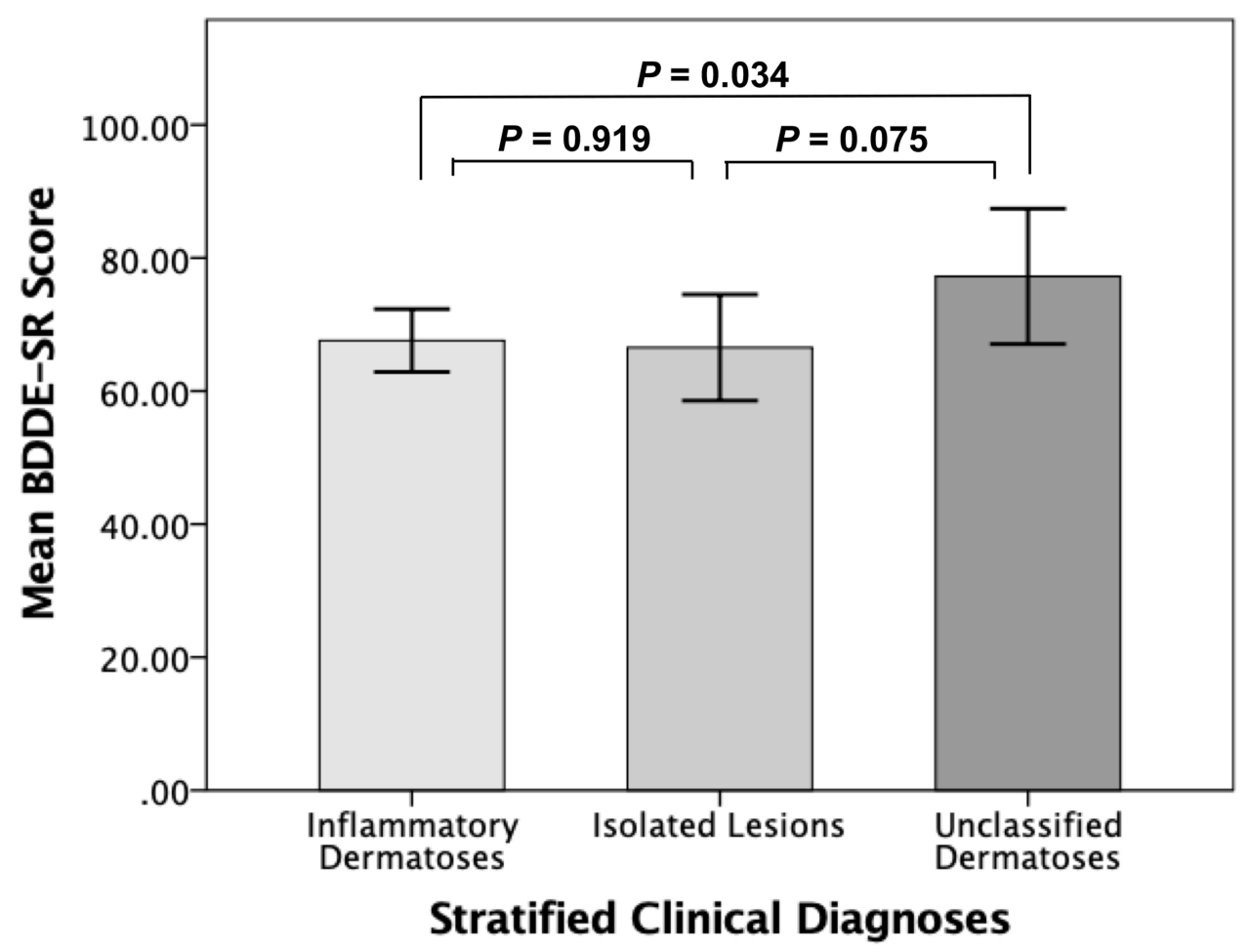

Figure 2 Bar plots of the relationships of BDDE-SR score with stratified dermatological diagnoses. 
rarely satisfactory (although they may be successful from a physician's point of view) because the treatments do not alleviate BDD symptoms. ${ }^{31,32}$ In a survey of cosmetic surgeons, $84 \%$ reported that they had operated on BDD patients, but only $1 \%$ of the cases resulted in complete remission of symptoms. ${ }^{33}$ Moreover, $40 \%$ of the respondents stated that BDD patients had threatened them with legal action, and/or physically. ${ }^{33}$ These findings suggest assessment for BDD may be needed before surgical and non-psychiatric medical treatments are provided.

The present study had several limitations. First, as this was a cross-sectional study, we could not make inferences regarding causality with respect to BDD symptoms, psychiatric symptoms, and quality of life. Further long-term follow-up studies are thus required. Second, this study was conducted in a dermatology clinic in South Korea, and the findings may not be generalizable to other clinical settings or countries. Last, we used self-report questionnaires for assessing BDD, psychiatric symptoms, and quality of life, rather than clinical diagnoses or interviews by psychiatrists. However, the Korean questionnaires used have high reliability and validity.

\section{Conclusions}

BDD symptoms were especially prominent in the unclassified dermatoses group and were highly related to psychiatric symptoms and low quality of life in our dermatological patients. Studies including psychiatric interviews to confirm the BDD diagnosis and symptoms will improve our understanding of BDD in dermatology patients.

\section{Acknowledgments}

This study was financially supported by the research fund of Chungnam National University in 2019. The funding source had no role in the study design, data collection, data analysis, data interpretation, writing of the manuscript, or decision to submit it for publication.

\section{Disclosure}

The authors report no conflicts of interest in this work.

\section{References}

1. Cororve MB, Gleaves DH. Body dysmorphic disorder: a review of conceptualizations, assessment, and treatment strategies. Clin Psychol Rev. 2001;21(6):949-970. doi:10.1016/S0272-7358(00)00075-1

2. American Psychiatric Association. Task force on DSM-IV. 4th ed. In: Diagnostic and Statistical Manual of Mental Disorders: Dsm-IV. Washington, DC: American Psychiatric Association; 1994.

3. American Psychiatric Association. Task force on DSM-5. In: Diagnostic and Statistical Manual of Mental Disorders DSM-5. Arlington, VA: American Psychiatric Association; 2013.
4. Gunstad J, Phillips KA. Axis I comorbidity in body dysmorphic disorder. Compr Psychiatry. 2003;44(4):270-276. doi:10.1016/ S0010-440X(03)00088-9

5. Phillips KA. Body dysmorphic disorder: recognizing and treating imagined ugliness. World Psychiatry. 2004;3(1):12-17.

6. DeMarco LM, Li LC, Phillips KA, McElroy SL. Perceived stress in body dysmorphic disorder. J Nerv Ment Dis. 1998;186(11):724-726. doi:10.1097/00005053-199811000-00011

7. Phillips KA. Quality of life for patients with body dysmorphic disorder. J Nerv Ment Dis. 2000;188(3):170-175. doi:10.1097/ 00005053-200003000-00007

8. Whoqol Group T. The World Health Organization Quality of Life Assessment (WHOQOL): development and general psychometric properties. Soc Sci Med. 1998;46(12):1569-1585. doi:10.1016/ S0277-9536(98)00009-4

9. Shumaker S,A, Berzon RA. The International Assessment of HealthRelated Quality of Life: Theory, Translation, Measurement and Analysis. New York: Rapid Communications; 1994.

10. Phillips KA, Dufresne RG, Wilkel CS, Vittorio CC. Rate of body dysmorphic disorder in dermatology patients. $J$ Am Acad Dermatol. 2000;42(3):436-441. doi:10.1016/S0190-9622(00)90215-9

11. Sarwer DB, Wadden TA, Pertschuk MJ, Whitaker LA. Body image dissatisfaction and body dysmorphic disorder in 100 cosmetic surgery patients. Plast Reconstr Surg. 1998;101(6):1644-1649. doi:10.1097/ 00006534-199805000-00035

12. Jones-Caballero M, Penas PF, Garcia-Diez A, Badia X, Chren MM. The Spanish version of Skindex-29. Int J Dermatol. 2000;39 (12):907-912. doi:10.1046/j.1365-4362.2000.00944.x

13. Kim DY, Lee JW, Whang SH, Park YK, Hann SK, Shin YJ. Quality of life for Korean patients with vitiligo: Skindex-29 and its correlation with clinical profiles. J Dermatol. 2009;36(6):317-322. doi:10.1111/j.1346-8138.2009.00646.x

14. Chren MM, Lasek RJ, Quinn LM, Mostow EN, Zyzanski SJ. Skindex, a quality-of-life measure for patients with skin disease: reliability, validity, and responsiveness. $J$ Invest Dermatol. 1996;107(5):707-713. doi:10.1111/1523-1747.ep12365600

15. Rosen JC, Reiter J, Orosan P. Assessment of body image in eating disorders with the body dysmorphic disorder examination. Behav Res Ther. 1995;33(1):77-84. doi:10.1016/0005-7967(94)E0030-M

16. Rosen JC, Reiter J. Development of the body dysmorphic disorder examination. Behav Res Ther. 1996;34(9):755-766. doi:10.1016/ 0005-7967(96)00024-1

17. Kim JL, Chee IS, Shin SC. Preliminary study or the development of a Korean version of the body dysmorphic disorder examination-self report (BDDE-SR). J Korean Neuropsychiatr Assoc. 1999;42(8):754. doi:10.5124/jkma.1999.42.8.754

18. Kim JW, Kim SY, Gang MH, et al. Body dysmorphic disorder in a Korean nurse college student sample. J Korean Soc Biol Ther Psychiatry. 2007;13:259-274.

19. Derogatis Leonard R. SCL-90-R: Administration, Scoring \& Procedures Manual-II for the Revised Version and Other Instruments of the Psychopathology Rating Scale Series. 2nd ed. Baltimore: Johns Hopkins University School of Medicine: Clinical Psychometric Research; 1983.

20. Kim JH, Kim GI. The standardization study of symptom checklist-90-revision in Korea III. Ment Health Res. 1984;2:278-311.

21. Chren MM, Lasek RJ, Flocke SA, Zyzanski SJ. Improved discriminative and evaluative capability of a refined version of Skindex, a quality-of-life instrument for patients with skin diseases. Arch Dermatol. 1997;133 (11):1433-1440. doi:10.1001/archderm.1997.03890470111018

22. Gill TM, Feinstein AR. A critical appraisal of the quality of quality-of-life measurements. JAMA. 1994;272(8):619-626. doi:10.1001/jama.1994.03520080061045

23. Ahn BK, Lee SJ, Namkoong K, Chung YL, Lee SH. The Korean version of Skindex-29. Korean J Dermatol. 2004;42(1):9-15. 
24. Qizilbash N, Gregson J, Johnson ME, et al. BMI and risk of dementia in two million people over two decades: a retrospective cohort study. Lancet Diabetes Endocrinol. 2015;3(6):431-436. doi:10.1016/S22138587(15)00033-9

25. Kaymak Y, Taner E, Simsek I. Body dysmorphic disorder in university students with skin diseases compared with healthy controls. Acta Derm Venereol. 2009;89(3):281-284. doi:10.2340/00015555-0638

26. Nierenberg AA, Phillips KA, Petersen TJ, et al. Body dysmorphic disorder in outpatients with major depression. J Affect Disord. 2002;69(1-3):141-148. doi:10.1016/S0165-0327(01)00304-4

27. Dogruk Kacar S, Ozuguz P, Bagcioglu E, et al. Frequency of body dysmorphic disorder among patients with complaints of hair loss. Int J Dermatol. 2016;55(4):425-429. doi:10.1111/ijd.12758

28. Phillips KA, McElroy SL, Keck PE, Pope HG, Hudson JI. Body dysmorphic disorder: 30 cases of imagined ugliness. $\mathrm{Am}$ J Psychiatry. 1993;150(2):302-308.

29. Conrado LA, Hounie AG, Diniz JB, et al. Body dysmorphic disorder among dermatologic patients: prevalence and clinical features. $\mathrm{J} \mathrm{Am}$ Acad Dermatol. 2010;63(2):235-243. doi:10.1016/j.jaad.2009.09.017
30. Phillips KA, Diaz SF. Gender differences in body dysmorphic disorder. J Nerv Ment Dis. 1997;185(9):570-577. doi:10.1097/ 00005053-199709000-00006

31. Phillips KA, Grant J, Siniscalchi J, Albertini RS. Surgical and nonpsychiatric medical treatment of patients with body dysmorphic disorder. Psychosomatics. 2001;42(6):504-510. doi:10.1176/appi. psy.42.6.504

32. Crerand CE, Phillips KA, Menard W, Fay C. Nonpsychiatric medical treatment of body dysmorphic disorder. Psychosomatics. 2005;46 (6):549-555. doi:10.1176/appi.psy.46.6.549

33. Sarwer DB. Awareness and identification of body dysmorphic disorder by aesthetic surgeons: results of a survey of american society for aesthetic plastic surgery members. Aesthet Surg J. 2002;22 (6):531-535. doi:10.1067/maj.2002.129451

\section{Publish your work in this journal}

Neuropsychiatric Disease and Treatment is an international, peerreviewed journal of clinical therapeutics and pharmacology focusing on concise rapid reporting of clinical or pre-clinical studies on a range of neuropsychiatric and neurological disorders. This journal is indexed on PubMed Central, the 'PsycINFO' database and CAS, and is the official journal of The International Neuropsychiatric Association (INA). The manuscript management system is completely online and includes a very quick and fair peer-review system, which is all easy to use. Visit http://www.dovepress.com/testimonials.php to read real quotes from published authors. 